\title{
Subunit Composition of Molecular Species of Legumin from the Broad Bean
}

\author{
Shigeru Utsumi and Tomohiko Mori \\ Research Institute for Food Science, Kyoto University, \\ Uji, Kyoto 611, Japan \\ Received March 19, 1981
}

\begin{abstract}
The molecular species of legumin from broad bean seeds exhibit wide heterogeneity [S. Utsumi and T. Mori, Biochim. Biophys. Acta, 621, 179 (1980)]. The subunit compositions of these molecular species were analyzed according to the following procedure: the molecular species were separated by polyacrylamide gel electrophoresis, and then their subunit compositions were analyzed by sodium dodecyl sulfate-polyacrylamide gel electrophoresis. The results indicated that five groups with nine kinds of submolecular species having different molecular weights and subunit compositions were present as legumin in the broad bean. According to these results, we have demonstrated the presence of another group consisting of two kinds of submolecular species, in addition to the four groups and seven kinds of submolecular species reported previously. Various possible molecular species of legumin composed of subunit groups classified according to size were presented.
\end{abstract}

Legumin is one of the predominant components of the storage proteins in various seeds. ${ }^{1)}$ The subunit structure of legumin from the broad bean has been studied by Wright and Boulter ${ }^{2)}$ and by us. ${ }^{3 \sim 5)}$ In var. Triple White, Wright and Boulter identified one molecular species composed of five distinct subunits, of which two were acidic (A) each with a molecular weight of 37,000 , and three basic (B) with molecular weights of $23,800,20,900$, and 20,100 . On the other hand, we have reported that four groups of legumin proteins with seven kinds of submolecular species having different molecular weights and subunit compositions are present in various broad bean cultivars, such as vars. Sanuki-Nagasaya, Kumamoto-Churyu and Otafuku. ${ }^{4)}$ The subunit compositions of legumins of these cultivars differ among themselves with respect to the molecular charges of their subunits. ${ }^{5)} \mathrm{We}$ have also observed such heterogeneity in glycinin, a legumin-like protein, obtained from various soybean cultivars. ${ }^{6}$

In the present study, we analyzed the legumin as follows: the molecular species were separated by polyacrylamide gel electrophoresis, and then the composition of their subunits was analyzed by sodium dodecyl sulfate-polyacrylamide gel electrophoresis. The results obtained here confirm and extend informations previously reported, in which the molecular species were not separated. ${ }^{4)}$ In this study, it was found that five groups with nine kinds of submolecular species are present as legumin in the broad bean, var. Otafuku.

\section{MATERIALS AND METHODS}

Sodium dodecyl sulfate (SDS) and 2-mercaptoethanol (2-ME), both specially prepared reagents, were obtained from Wako Pure Chemical Industries and Nakarai Chemicals, respectively. Other chemicals were guaranteed reagent grade. Seeds of Vicia faba var. Otafuku were purchased from Takii Seed Co. Ltd.

Purified legumin was prepared from meal extract as described previously. ${ }^{3,4)}$

Analysis of subunit compositions of the molecular species of legumin. The analysis of the composition of the subunits of the molecular species of legumin was carried out by combining two disc electrophoresis systems with polyacrylamide gel electrophoresis (PAGE) and SDS-PAGE as described by Kanda et al., ${ }^{7}$ with a slight modification. As described in a previous paper, ${ }^{3)} 20 \mu \mathrm{g}$ protein, dialyzed against $50 \mathrm{~mm}$ potassium phosphate buffer $(\mathrm{pH} 7.6)$ containing $0.2 \mathrm{M} \mathrm{NaCl}$ at $4^{\circ} \mathrm{C}$, was electrophoresed on 
polyacrylamide gel (PAG) using $0.6 \times 10 \mathrm{~cm}$ glass tube according to the method of Davis. ${ }^{81}$ After the electrophoresis, the gel was stained with $0.5 \%$ amidoblack $10 \mathrm{~B}$ in $20 \%$ acetic acid for $5 \mathrm{~min}$ and destained with $7 \%$ acetic acid. The protein bands were cut off, rinsed with $63.5 \mathrm{~mm}$ Tris- $\mathrm{HCl}$ buffer ( $\mathrm{pH} \mathrm{6.8)}$ containing $1 \%$ SDS, 0.2 м 2-ME and $30 \%$ sucrose for $30 \mathrm{~min}$ at room temperature, and rinsed again for another $30 \mathrm{~min}$ at $50^{\circ} \mathrm{C}$ with a change of the buffer. The incubated gel slices were placed on the top of a SDS-PAG in a $0.6 \times 10 \mathrm{~cm}$ glass tube, and a trace amount of tracking dye $(0.02 \%$ bromophenol blue in the buffer) was layered on the gel slices. SDS-PAGE was performed according to the procedure of Laemmili ${ }^{9)}$ as described previously. ${ }^{3)}$

The destained gels were scanned at $590 \mathrm{~nm}$ on a Shimadzu dual-wavelength chromatoscanner, model CS910 .

\section{RESULTS AND DISCUSSION}

As described previously, ${ }^{3,4)}$ the $11 \mathrm{~S}$ component fraction of broad bean meal extract was prepared by sucrose density gradient centrifugation and then applied to a DEAESephadex A-50 column. As shown in Fig. 1, the molecular species of the legumin fraction varied in kind and in number according to elution position. This observation confirms our previous results. ${ }^{4}$ The protein bands separated by PAGE were numbered according to their order of elution from the DEAESephadex column and to their electrophoretic mobilities. Each band was analyzed by SDSPAGE and the SDS-PAGE pattern of each protein band is shown in Fig. 2. The relative amount of each band observed on SDS-PAG was estimated densitometrically, and the results are listed in Table I.

As shown in Fig. 1, various bands had the same mobilities on PAGE, e. g., bands 2 and, 4; 3,6 and 9; 5, 8,11 and 15; and 7, 10 and 14 . However, bands 2 and 4; 3,6 and 9; and 5 and 8 gave similar SDS-PAGE patterns, respectively, while bands 8 (or 5), 11 and 15 , and 7, 10 and 14 gave fairly different patterns (Fig. 2 and Table I). This result suggests that in the broad bean there are some molecular species with the same mobility on PAGE but with different subunit compositions.

We attempted to list the possible molecular species of legumin constructed from the subunit groups classified according to their sizes. The possible molecular species are shown in Table II. Each subunit composition was deduced from the results obtained in this investigation (Table I) and experimental evidence (subunit compositions of intermediary subunits) obtained previously, ${ }^{4)}$ along with the assumption that all the molecular. species of legumin are composed of $\mathrm{A}_{6} \mathrm{~B}_{6}$ which had been found in glycinin of Glycine max, ${ }^{10 \sim 12)}$

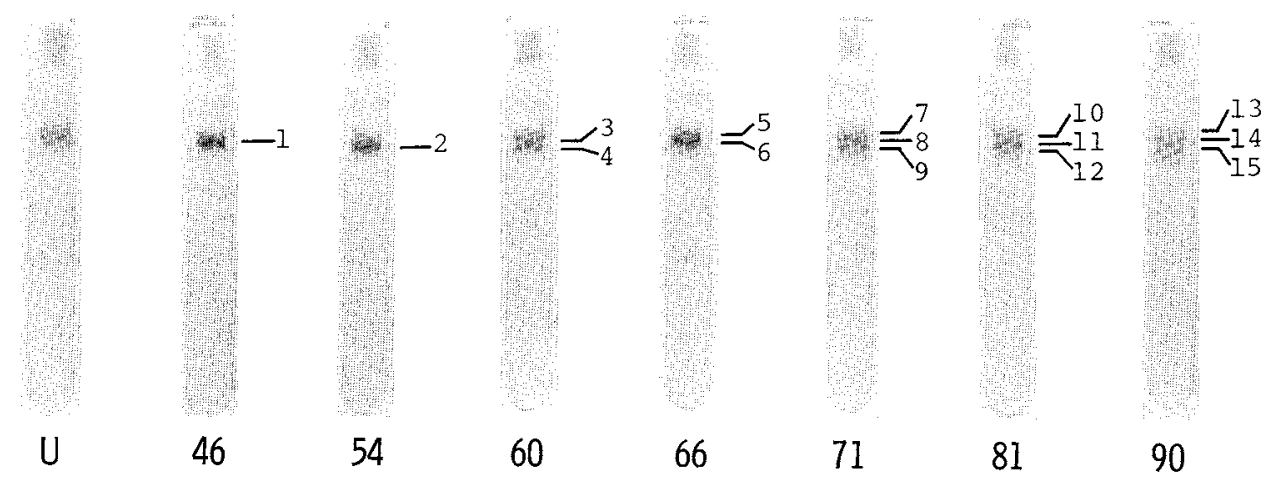

FIG. 1. Polyacrylamide Gel Electrophoresis of Legumin Fractions from DEAE-Sephadex Column Chromatography.

Twenty $\mu \mathrm{g}$ protein from each fraction was dialyzed against $50 \mathrm{~mm}$ potassium phosphate buffer (pH 7.6) containing $0.2 \mathrm{M} \mathrm{NaCl}$ at $4{ }^{\circ} \mathrm{C}$ and then electrophoresed as described in Materials AND Methods. U refers to an unfractionated sample. The numbers under the gels are the fraction numbers from the DEAE-Sephadex column chromatography. The protein bands separated by this electrophoresis were numbered as described in the text. Migration is from top to bottom. 


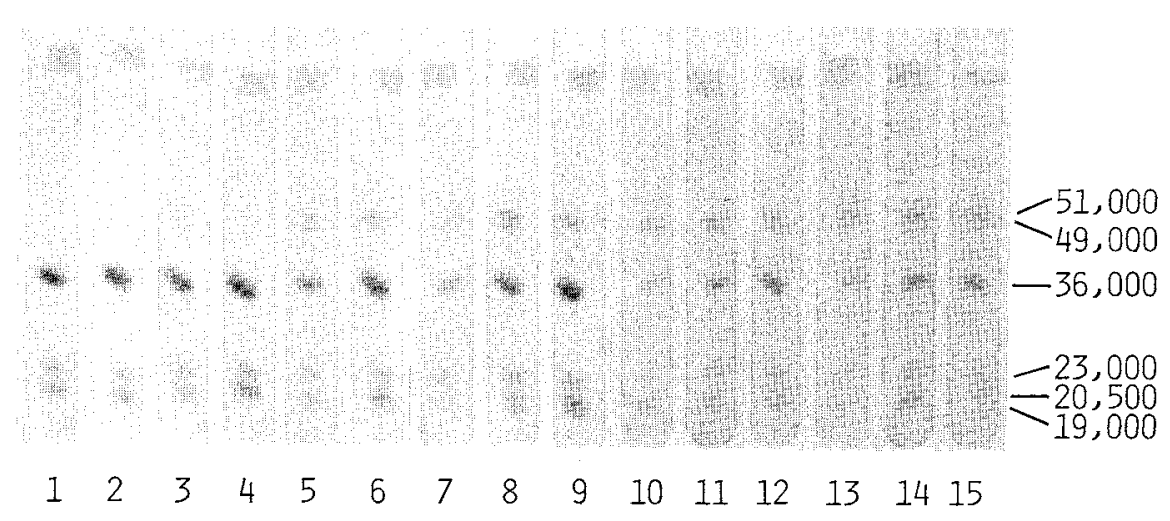

FIG. 2. SDS-Polyacrylamide Gel Electrophoresis of Protein Bands Separated by PAGE.

Each stained protein band separated by PAGE (Fig. 1) was cut off and electrophoresed as described in Materials AND METHODS. The number of gel slices used (two to four) was dependent on the intensity of the stained band. Migration is from top to bottom.

Table I. Relative Amounts of Subunits in Each Protein Band Separated by Page

The amounts were estimated densitometrically, relative to the basic subunit with molecular weight of 23,000 which was taken as unity.

\begin{tabular}{|c|c|c|c|c|c|c|}
\hline \multirow{2}{*}{ Gel No. } & \multicolumn{3}{|c|}{ Acidic subunits with molecular weights of } & \multicolumn{3}{|c|}{ Basic subunits with molecular weights of } \\
\hline & 51,000 & 49,000 & 36,000 & 23,000 & 20,500 & 19,000 \\
\hline 1 & - & - & 2.94 & 1 & 1.21 & - \\
\hline 2 & - & - & 3.24 & 1 & 1.59 & - \\
\hline 3 & 0.29 & 0.18 & 3.57 & 1 & 1.21 & 0.11 \\
\hline 4 & - & - & 3.15 & 1 & 1.89 & - \\
\hline 5 & 0.47 & 0.35 & 2.94 & 1 & 0.84 & 0.78 \\
\hline 6 & 0.32 & 0.17 & 2.32 & 1 & 1.44 & 0.65 \\
\hline 7 & 0.77 & 0.62 & 2.56 & 1 & 0.26 & 1.05 \\
\hline 8 & 0.68 & 0.32 & 2.50 & 1 & 0.63 & 0.83 \\
\hline 9 & 0.71 & 0.14 & 3.57 & 1 & 1.32 & 0.36 \\
\hline 10 & 1.51 & 0.52 & 2.05 & 1 & 0.21 & 1.18 \\
\hline 11 & 1.15 & 0.47 & 1.80 & 1 & 0.42 & 1.52 \\
\hline 12 & 0.72 & 0.55 & 2.35 & 1 & 0.78 & 0.96 \\
\hline 13 & 1.66 & 0.38 & 2.13 & 1 & 0.18 & 1.34 \\
\hline 14 & 1.05 & 0.28 & 1.80 & 1 & 0.33 & 1.48 \\
\hline 15 & 0.82 & 0.25 & 2.17 & 1 & 0.98 & 0.85 \\
\hline
\end{tabular}

$12 \mathrm{~S}$ globulin of Avena sativa, ${ }^{13)} \alpha$-globulin of Sesamum indicum, ${ }^{14)}$ arachin of Arachis $h y$ pogaea, ${ }^{15)}$ legumin of Pisum sativum ${ }^{16,17)}$ and others. ${ }^{18)}$ The presence of two other molecular species in addition to those molecular species shown in previously ${ }^{4)}$ could be deduced from the results described above (group IV in Table II). The molecular weight of each molecular species, calculated from the molecular weight for each subunit, is also listed in Table II.
Thus, five groups of molecular species with different molecular weights are present in the broad bean. However, in our previous paper, we found four groups of molecular species by polyacrylamide gradient gel electrophoresis. This discrepancy can be due to the closeness of the molecular weights of group III $(370,000)$ and group IV $(380,000)$, or to the fact that both groups have similar apparent molecular sizes. 
Table II. The Possible Molecular Species of legumin in the Broad Bean

\begin{tabular}{|c|c|c|c|}
\hline \multirow{2}{*}{$\begin{array}{l}\text { Moleculat } \\
\text { species }\end{array}$} & \multirow{2}{*}{ Subunit composition* } & \multicolumn{2}{|c|}{ Molecular weights } \\
\hline & & Calculated** & Observed ${ }^{* * *}$ \\
\hline $\begin{array}{l}I-1 \\
I-2\end{array}$ & $\begin{array}{l}3\left(A_{3} B_{1}\right) 3\left(A_{3} B_{2}\right) \\
2\left(A_{3} B_{1}\right) 4\left(A_{3} B_{2}\right)\end{array}$ & 345,000 & 320,000 \\
\hline $\begin{array}{l}\text { II-1 } \\
\text { II }-2\end{array}$ & $\begin{array}{l}2\left(A_{3} B_{1}\right) 3\left(A_{3} B_{2}\right) l\left(A_{2} B_{3}\right) \\
2\left(A_{3} B_{1}\right) 3\left(A_{3} B_{2}\right) \quad 1\left(A_{1} B_{3}\right)\end{array}$ & 357,000 & 350,000 \\
\hline $\begin{array}{l}\text { III-1 } \\
\text { III-2 } \\
\text { IV }-1 \\
\text { IV }-2\end{array}$ & 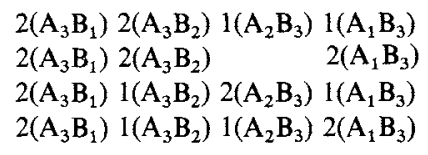 & 380,000 & 380,000 \\
\hline $\mathrm{V}-1$ & $1\left(A_{2} B_{3}\right) 3\left(A_{1} B_{3}\right)$ & 396,000 & 400,000 \\
\hline
\end{tabular}

* The subunits with molecular weights of $51,000,49,000,36,000,23,000,20,500$ and 19,000 shown in Fig. 2 were termed $A_{1}, A_{2}, A_{3}, B_{1}, B_{2}$ and $B_{3}$, respectively.

** Calculated from molecular weight of each subunit.

*** Estimated from the results of the gradient gel electrophoresis. ${ }^{4)}$

A legumin preparation, which had not been fractionated by DEAE-Sephadex column chromatography, gave one broad band on PAGE (Fig. 1, Gel U). Thus, it was not until such fractionation was carried out prior to PAGE that the heterogeneity of the molecular species of legumin could be observed. It may be difficult to elucidate the subunit compositions of protein bands separated by PAGE precisely with standard two dimensional electrophoresis, since the bands were not separated from each other by any significant distance. However, if the method of Kanda et al. ${ }^{7)}$ is used as it was in this investigation, the elucidation of the protein band appears to be easy, since the procedure eliminates possible cross contamination of proteins during the excision of the unstained gel. In fact, with this method we found the presence of group IV, which had been missed in previous experiments in which the subunit composition of each molecular species was deduced without their separation by PAGE. ${ }^{4)}$

\section{REFERENCES}

1) C. E. Danielsson, Biochem. J., 44, 387 (1949).
2) D. J. Wright and D. Boulter, Biochem. J., 141, 413 (1974).

3) T. Mori and S. Utsumi, Agric. Biol. Chem., 43, 577 (1979).

4) S. Utsumi and T. Mori, Biochim. Biophys. Acta, 621, 179 (1980).

5) S. Utsumi, Z. Yokoyama and T. Mori, Agric. Biol. Chem., 44, 595 (1980).

6) S. Utsumi, H. Inaba and T. Mori, Phytochemistry, 20, 585 (1981).

7) F. Kanda, H. Ochiai and M. Iwabuchi, Eur. J. Biochem., 44, 469 (1974).

8) B. J. Davis, Ann. N. Y. Acad. Sci., 121, 404 (1964).

9) U. K. Laemmli, Nature, 227, 680 (1970).

10) N. Catsimpoolas, FEBS Lett., 4, 259 (1969).

11) R. A. Badley, D. Atkinson, H. Hauser, D. Oldani, J. P. Green and J. M. Stubbs, Biochim. Biophys. Acta, 412, 214 (1975).

12) K. Kitamura, T. Takagi and K. Shibasaki, Agric. Biol. Chem., 40, 1837 (1976).

13) D. M. Peterson, Plant Physiol., 62, 506 (1978).

14) K. Hasegawa, M. Murata and S. Fujino, Agric. Biol. Chem., 42, 2291 (1978).

15) T. Yamada, S. Aibara and Y. Morita, Agric. Biol. Chem., 43, 2563 (1979).

16) R. Casey, Biochem. J., 177, 509 (1979).

17) J. A. Gatehouse, R. R. D. Croy and D. Boulter, Biochem. J., 185, 497 (1980).

18) E. Derbyshire, D. J. Wright and D. Boulter, Phytochemistry, 15, 3 (1976). 